\title{
Blockade of nicotinic receptor-mediated release of dopamine from striatal synaptosomes by chlorisondamine administered in vivo
}

\author{
H. El-Bizri \& 'P.B.S. Clarke
}

Department of Pharmacology and Therapeutics, McGill University, 3655 Drummond St, Montreal, Canada H3G 1Y6

1 The chronic nicotinic blockade produced following in vivo administration of chlorisondamine was investigated in vitro. Nicotine-induced $\left[{ }^{3} \mathrm{H}\right]$-dopamine release from striatal synaptosomes was used as a measure of central nicotinic receptor function.

2 In synaptosomal preparations from rats pretreated with a single administration of chlorisondamine $\left(10 \mathrm{mg} \mathrm{kg}^{-1}\right.$, s.c.), 1, 7, 21, 42, 63 or 84 days before they were killed, responses to (-)-nicotine $\left(10^{-6} \mathrm{M}\right)$ were blocked.

3 In vivo administration of chlorisondamine $\left(10 \mathrm{mg} \mathrm{kg}^{-1}, \mathrm{s.c}\right.$.), 7 days before rats were killed, produced a nicotinic blockade in vitro that was insurmountable even with a high concentration of (-)-nicotine $\left(10^{-4} \mathrm{M}\right)$.

4 Both in vitro and in vivo administration of chlorisondamine blocked nicotinic responses to acetylcholine $\left(10^{-4} \mathrm{M}\right)$. In contrast, neither in vitro nor in vivo administration of chlorisondamine reduced $\left[{ }^{3} \mathrm{H}\right]$-dopamine release induced by high $\mathrm{K}^{+}\left(20 \times 10^{-3} \mathrm{M}\right)$ or $(+)$-amphetamine $\left(10^{-6} \mathrm{M}\right)$.

5 Nicotinic blockade resulting from in vitro administration of chlorisondamine $\left(10^{-5} \mathrm{M}\right)$ recovered partially after $60 \mathrm{~min}$ wash-out, and completely by $90 \mathrm{~min}$. In contrast, no recovery was seen in synaptosomes prepared from rats pretreated with chlorisondamine $\left(10 \mathrm{mg} \mathrm{kg}^{-1}\right.$, s.c.) in vivo.

6 Thus, in vivo treatment with chlorisondamine results in a quasi-irreversible, insurmountable block of CNS nicotinic receptors. The persistence of this block ex vivo indicates that physical trapping by the blood brain barrier is not solely responsible for the persisent blockade seen in vivo. The resistance of this blockade to prolonged in vitro wash-out suggests that the underlying mechanism differs from that associated with in vitro administration.

Keywords: Chlorisondamine; nicotine; acetylcholine; dopamine; nicotinic receptors; nicotinic; transmitter release

\section{Introduction}

Chlorisondamine (CHL) is a ganglionic nicotinic receptor antagonist (Plummer et al., 1955) which has been used clinically as an antihypertensive (Boura \& Green, 1984). Studies in rats have shown that central administration of CHL (5 or $10 \mu \mathrm{g} \mathrm{kg}^{-1}$ i.c.v.) results in a blockade of a variety of behavioural effects of nicotine that are mediated via CNS nicotinic receptors (Clarke \& Kumar, 1983; Clarke, 1984; Reavill et al., 1986; Fudala \& Iwamoto, 1987; Kumar et al., 1987; Mundy \& Iwamoto, 1988; Corrigall et al., 1992). This blockade is remarkably persistent, lasting at least 5 weeks after a single administration of CHL (Clarke, 1984). Although CHL is a bisquaternary amine and appears to penetrate the CNS poorly, administration of a sufficiently large systemic dose $\left(10 \mathrm{mg} \mathrm{kg}{ }^{-1}\right.$, s.c.) also results in a longlasting central nicotinic blockade (Clarke, 1984; Clarke et al., 1994), whereas ganglion blockade is only transient (Clarke et al., 1994).

The mechanism underlying this persistent central antagonism is not known. The blockade is selective, insofar as administration of $\mathrm{CHL}$ did not reduce the behavioural effects of non-nicotinic agents such as apomorphine, midazolam, morphine, cocaine or amphetamine (Reavill et al., 1986; Kumar et al., 1987; Corrigall et al., 1992). The apparent absence of recovery from central nicotinic blockade (Clarke, 1984) suggested the possibility of a neurotoxic mechanism, but in a companion paper (Clarke et al., 1994), we present evidence that $\mathrm{CHL}$ does not cause neuronal degeneration. In addition, the persistent central blockade produced by CHL was not accompanied by a change in the

\footnotetext{
${ }^{1}$ Author for correspondence.
}

density of $\left.{ }^{3} \mathrm{H}\right]$-nicotine binding sites in rat forebrain (Clarke et al., 1994).

In the preceding paper (El-Bizri \& Clarke, 1994), we characterized the nicotinic blockade produced by acute, in vitro administration of CHL. Nicotinic receptor function was assayed by measuring nicotine-induced release of $\left[{ }^{3} \mathrm{H}\right]-$ dopamine from rat striatal synaptosomes. In the present study, we use the same assay in order to examine the mechanisms underlying the persistent block of central nicotinic responses that follows in vivo administration of CHL. By testing nicotinic responses in synaptosomes prepared from rats that had received CHL in vivo, it was possible to test whether this persistent central blockade is due solely to physical trapping of the drug (or, possibly, a metabolite) by the blood brain barrier. The chronic blockade produced by in vivo administration of CHL was compared to the acute blockade produced by in vitro administration of the drug.

\section{Methods}

Full details of the procedures for synaptosomal preparation and superfusion are given in an accompanying paper (ElBizri \& Clarke, 1994).

\section{Data analysis}

Basal and drug-induced dopamine release were calculated as in the preceding paper (El-Bizri \& Clarke, 1994). Statistical results refer to tests of analysis of variance, made using commercial software (Systat, Evanston, IL, U.S.A.). 


\section{Drugs}

Drugs were as described in the preceding paper (El-Bizri \& Clarke, 1994), except as follows. (+)-Amphetamine sulphate was supplied by Smith, Kline and French (Canada). For in vivo administration, chlorisondamine chloride (CHL) was dissolved in $0.9 \% \mathrm{w} / \mathrm{v} \mathrm{NaCl}$ solution (saline). Injections were given s.c. in a volume of $1 \mathrm{ml} \mathrm{kg}^{-1}$, and the dose refers to the base. For in vitro administration, drugs were dissolved in superfusion buffer (SB).

\section{Procedures}

Persistence of $\mathrm{CHL}$ blockade ex vivo: effect of survival duration Animals in each of six groups were randomly allocated for pretreatment with CHL $\left(10 \mathrm{mg} \mathrm{kg}^{-1}\right.$, s.c., $n=4$ per survival time) or saline (s.c., $n=4$ per survival time), and were killed $1,7,21,42,63$ or 84 days later, depending on the group. Synaptosomes from each pretreated animal were tested with nicotine $\left(10^{-6} \mathrm{M} ; 2\right.$ or 3 channels per rat) and SB ( 1 or 2 channels per rat). Ten minutes later all channels received a $1 \mathrm{~min}$ pulse of $\mathrm{SB}$ containing high $\mathrm{KCl}$ $\left(20 \times 10^{-3} \mathrm{M}\right)$.

Surmountable vs insurmountable blockade by CHL ex vivo As above, rats were randomly allocated for pretreatment with CHL (10 $\mathrm{mg} \mathrm{kg}^{-1}$ s.c., $\left.n=4\right)$ or saline (Sal, $\left.n=4\right)$. They were killed one week later. Synaptomes prepared from these animals were superfused with a range of nicotine concentrations $\left(10^{-7}-10^{-4} \mathrm{M}\right)(1$ or 2 channels per condition per rat).

Selectivity of blockade by CHL: investigated after in vitro or in vivo administration Six rats were used: four received saline and two received CHL $\left(10 \mathrm{mg} \mathrm{kg}^{-1}\right.$, s.c.) one week before they were killed. In order to test blockade following in vitro administration of $\mathrm{CHL}$, synaptosomes from the salinepretreated rats were allocated to two groups of channels. One group was superfused for $25 \mathrm{~min}$ with SB, and the other group received SB containing CHL $\left(10^{-5} \mathrm{M}\right)$ before administration of test drugs. In order to test blockade following in vivo administration of $\mathrm{CHL}$, synaptosomes from rats treated with CHL in vivo were perfused for $25 \mathrm{~min}$ with $\mathrm{SB}$ prior to challenge. Thus there were three in vivo/in vitro pretreatment conditions: Sal/SB, Sal/CHL, and CHL/SB. Synaptosomal preparations were then challenged acutely with $\mathrm{SB}$, acetylcholine (ACh; $\left.10^{-4} \mathrm{M}\right),(+)$-amphetamine $\left(10^{-6} \mathrm{M}\right)$ or high $\mathrm{K}^{+}$buffer $\left(20 \times 10^{-3} \mathrm{M}\right)$, in a counterbalanced set of 4 assays. Thus, there were 12 combinations of pretreatment and treatment (4-5 channels per condition). In order to inhibit hydrolysis and possible muscarinic actions of $\mathrm{ACh}$, diisopropylfluorophosphate (DFP; $10^{-4} \mathrm{M}$ ) and atropine $\left(10^{-6} \mathrm{M}\right)$ were added to the superfusion buffer, and these compounds were present throughout all conditions.

Recovery from blockade by CHL after in vitro and in vivo administration First, recovery from blockade was tested following in vitro administration of CHL. Nicotinic responses were examined after a $30 \mathrm{~min}$ period of wash-out, as follows: in a set of 3 assays using 6 rats, synaptosomes were allocated to two groups of channels, receiving either SB or SB containing CHL $\left(10^{-5} \mathrm{M}\right)$ for a period of $35 \mathrm{~min}$. Next, equal numbers of channels in each group were perfused with either $\mathrm{SB}$ or nicotine $\left(10^{-6} \mathrm{M}\right)$. A washout period of $30 \mathrm{~min}$ followed, during which all channels contained SB. A second dose of SB or nicotine $\left(10^{-6} \mathrm{M}\right)$ was then given, allocated randomly but in equal number to channels that had previously received SB or nicotine. The procedure was repeated in a second set of 3 assays, except that the wash-out time was extended to $60 \mathrm{~min}$.

Subsequently, the extent of recovery from blockade was compared following in vivo vs in vitro administration of CHL. In three counterbalanced assays, using 6 rats, synap-
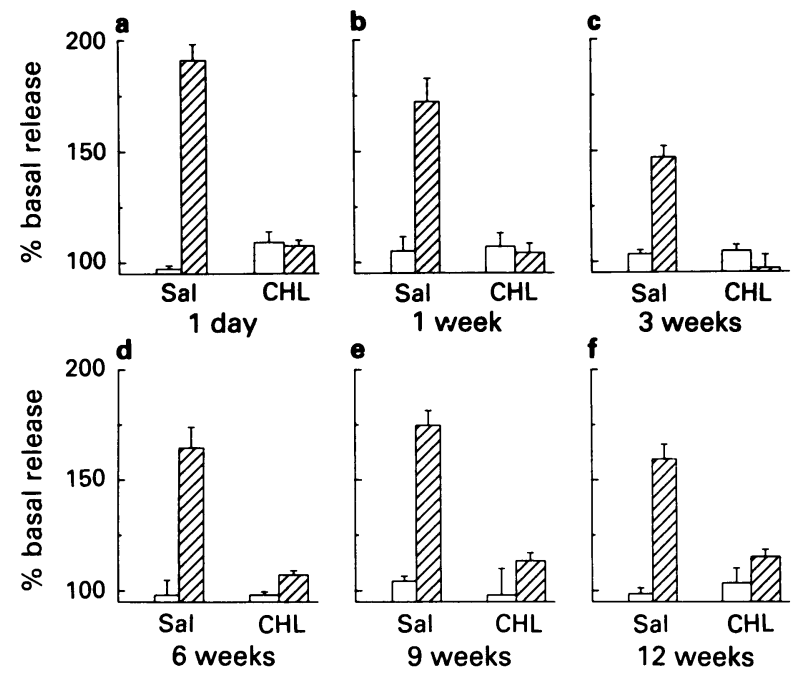

Figure 1 Effects of in vivo chlorisondamine (CHL) pretreatment on (-)-nicotine-induced $\left[{ }^{3} \mathrm{H}\right]$-dopamine release from rat striatal synaptosomes. Rats received a single pretreatment with CHL $\left(10 \mathrm{mg} \mathrm{kg}^{-1}\right.$, s.c.) or saline and were permitted to survive for different periods before they were killed: (a) 1; (b) 7; (c) 21 ; (d) 42; (e) 63 or (f) 84 days. Synaptosomes were superfused with superfusion buffer (SB) for $35 \mathrm{~min}$ prior to administration of a $1 \mathrm{~min}$ pulse of (-)-nicotine $\left(10^{-6} \mathrm{M}\right)$ (hatched columns) or SB (open columns). The vertical axis represents the mean ( \pm s.e.mean) peak release, calculated as a percentage of basal release ( $n=4$ rats).

tosomes were allocated to three groups of channels, corresponding to combinations of in vivo and in vitro pretreatment, as above: Sal/SB, Sal/CHL and CHL/SB. Following the $35 \mathrm{~min}$ in vitro pretreatment period, equal numbers of channels in each group received $\mathrm{SB}$ or nicotine $\left(10^{-6} \mathrm{M}\right)$. After a wash-out period of $90 \mathrm{~min}$, a second nicotine or SB superfusion was made. Channels that had previously received a SB challenge now received nicotine $\left(10^{-6} \mathrm{M}\right)$, and vice-versa. The experiment was repeated in another set of 6 assays, using a higher in vitro dose of $\mathrm{CHL}\left(10^{-4} \mathrm{M}\right)$, which resulted in a complete nicotinic blockade.

\section{Results}

\section{Persistence of CHL blockade ex vivo: effect of survival duration}

A complete block of nicotinic responses was observed ex vivo, even several weeks after single administration of $\mathrm{CHL}$ (10 $\mathrm{mg} \mathrm{kg}^{-1}$ s.c.). Thus, striatal synaptosomes prepared from rats that had been pretreated with CHL and permitted to survive for between one day and 12 weeks, failed to release $\left[{ }^{3} \mathrm{H}\right]$-dopamine when stimulated by $10^{-6} \mathrm{M}$ nicotine (Figure 1). CHL pretreatment had little if any effect on $\mathrm{K}^{+}$-induced

Table 1 High $\mathrm{K}^{+}$-induced $\left[{ }^{3} \mathrm{H}\right]$-dopamine release* from saline (Sal) or chlorisondamine (CHL) pretreated rats

Survival time (days) Sal pretreatment $\quad$ CHL $\dagger$ pretreatment

7

21

63 84

$\begin{array}{ll}180 \pm 11 & 193 \pm 6 \\ 186 \pm 18 & 213 \pm 19 \\ 187 \pm 15 & 178 \pm 9 \\ 200 \pm 19 & 203 \pm 22 \\ 219 \pm 9 & 209 \pm 20 \\ 190 \pm 10 & 199 \pm 14\end{array}$

*Mean ( \pm s.e.mean) peak release, calculated as a percentage of basal release $(n=4)$, in response to $\mathrm{K}^{+} 20 \mathrm{mM}$. †Dose (10 $\mathrm{mg} \mathrm{kg}^{-1}$, s.c.). 
$\left[{ }^{3} \mathrm{H}\right]$-dopamine release at any of the time points tested (Table 1). CHL pretreatment did not alter the basal release $(P>0.2)$, irrespective of survival time $(P>0.5)$.

\section{Surmountable vs insurmountable blockade by $C H L$ ex} vivo

As shown in Figure 2, blockade produced by in vivo $\mathrm{CHL}$ pretreatment was complete, and was insurmountable, even when tested with a high concentration $\left(10^{-4} \mathrm{M}\right)$ of nicotine.

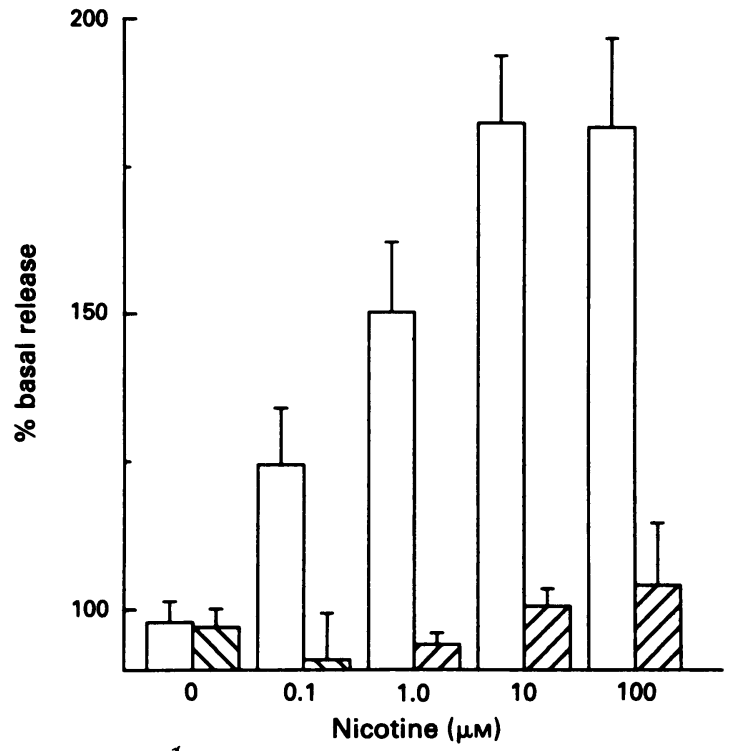

Figure 2 Effects of in vivo chlorisondamine (CHL) pretreatment (hatched columns) on $(-)$-nicotine-induced $\left[{ }^{3} \mathrm{H}\right]$-dopamine release from rat striatal synaptosomes. Rats received a single pretreatment with CHL $\left(10 \mathrm{mg} \mathrm{kg}^{-1}\right.$, s.c.) (hatched columns) or saline (open columns) one week before they were killed. Synaptosomes were superfused for $35 \mathrm{~min}$ prior to a $1 \mathrm{~min}$ pulse of $(-)$-nicotine or superfusion buffer. The values represents the mean ( \pm s.e.mean) peak release, calculated as a percentage of basal release ( $n=4$ rats).

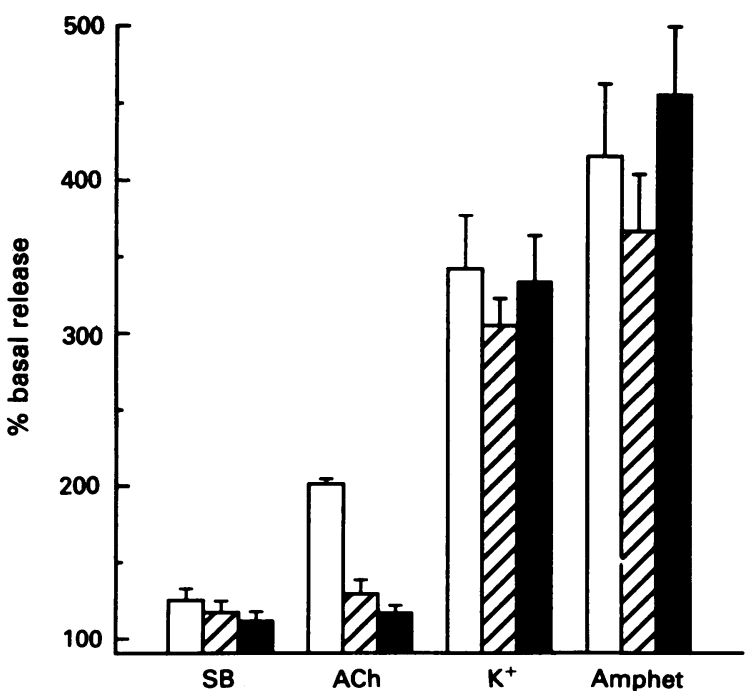

Figure 3 Effects of in vivo or in vitro chlorisondamine (CHL) pretreatment on $\left[{ }^{3} \mathrm{H}\right]$-dopamine release induced by nicotinic and non-nicotinic agents, from rat striatal synaptosomes. Rats received a single pretreatment with $\mathrm{CHL}\left(10 \mathrm{mg} \mathrm{kg}{ }^{-1}\right.$, s.c.) or saline one week before they were killed. Synaptosomes from the saline-pretreated rats were superfused with superfusion buffer (SB) (Sal/SB, open columns) or SB containing $\mathrm{CHL}\left(10^{-5} \mathrm{M}\right)(\mathrm{Sal} / \mathrm{CHL}$, hatched columns). Synaptosomes from CHL-pretreated rats were superfused with SB (CHL/SB, solid columns). Synaptosomes were superfused in this way for $35 \mathrm{~min}$ prior to a $1 \mathrm{~min}$ pulse of $\mathrm{SB}$ alone, acetylcholine $(\mathrm{ACh}$, $10^{-4} \mathrm{M}$ ), (+)-amphetamine (Amphet, $10^{-6} \mathrm{M}$ ) or high $\mathrm{K}^{+}$buffer $\left(20 \times 10^{-3} \mathrm{M}\right)$. The vertical axis represents the mean $( \pm$ s.e.mean) peak release, calculated as a percentage of basal release $(n=6-12)$.
Blockade by CHL after in vitro or in vivo administration

In control synaptosomes that had not been exposed to CHL, the three stimuli $\left(\mathrm{ACh},(+)\right.$-amphetamine, high $\left.\mathrm{K}^{+}\right)$produced different peak amounts of $\left[{ }^{3} \mathrm{H}\right]$-dopamine release (Figure 3). Prior exposure to $\mathrm{CHL}$, either in vivo or in vitro, did not reduce responses to high $\mathrm{K}^{+}$or (+)-amphetamine. However, prior exposure to CHL resulted in a complete blockade of responses to $\mathrm{ACh}$, and this was the case whether $\mathrm{CHL}$ had been given in vivo or in vitro (Figure 3).

Recovery from blockade following in vitro administration of CHL occurred slowly. The extent of recovery did not differ between channels that had received a pre-wash pulse of nicotine and those that had not. After $30 \mathrm{~min}$ wash-out no recovery was seen (Figure 4a), but after $60 \mathrm{~min}$ wash-out partial recovery was observed (Figure 4b). This is confirmed statistically, as follows. After a $30 \mathrm{~min}$ wash-out, CHLpretreated channels failed to show a nicotinic effect (Tukey's test: $P>0.9$ ). After a $60 \mathrm{~min}$ wash-out, CHL-pretreated channels were now stimulated by nicotine (Tukey's test: $P<0.01)$ but this nicotinic effect was less than in channels that had not received CHL (ANOVA $P<0.05$ ).

When in vivo and in vitro $\mathrm{CHL}$ treatments were subse-
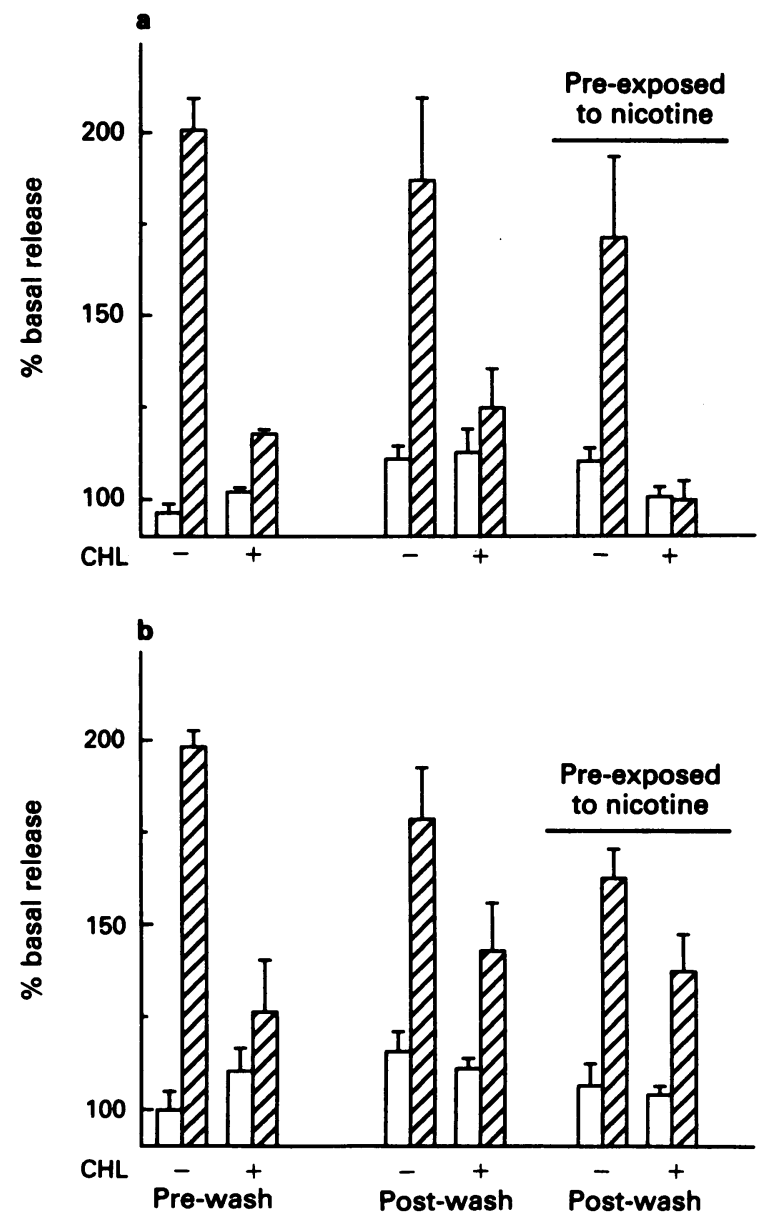

Figure 4 Effects of wash-out with superfusion buffer (SB) on nicotinic blockade produced by in vitro chlorisondamine (CHL) administration. Synaptosomes were either superfused with SB or SB containing $\mathrm{CHL}\left(10^{-5} \mathrm{M}\right)$ for $35 \mathrm{~min}$, followed by the first challenge (a 1 min pulse of $(-)$-nicotine $10^{-6} \mathrm{M}$ or $\mathrm{SB}$ ). All channels were then washed with SB alone for $30 \mathrm{~min}$ (a) or $60 \mathrm{~min}$ (b), followed by a second challenge with (-)-nicotine $\left(10^{-6} \mathrm{M}\right)$ (hatched columns) or SB (open columns), in a counterbalanced manner. Pre-exposed to nicotine, denotes the channels that were initially challenged with nicotine rather than SB. The vertical axis represents mean ( \pm s.e.mean) peak release, calculated as a percentage of basal release $(n=6-12)$. 

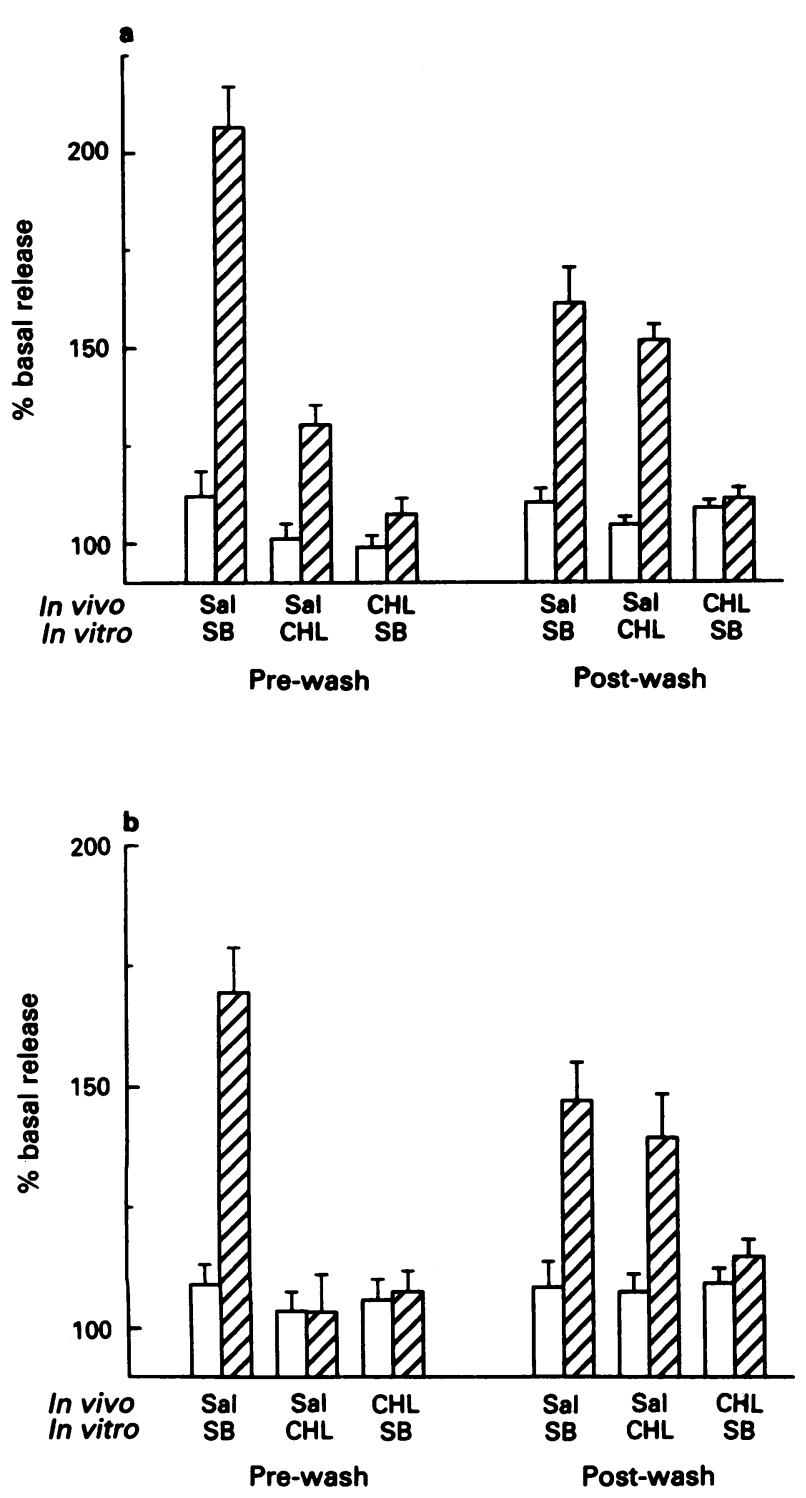

Figure 5 Effects of 90 min wash-out with superfusion buffer (SB) on nicotonic blockade, produced by in vitro or in vivo chlorisondamine (CHL) administration. Rats received a single pretreatment with CHL $\left(10 \mathrm{mg} \mathrm{kg}{ }^{-1}\right.$, s.c.) or saline one week before they were killed. Synaptosomes from the saline-pretreated rats were superfused with SB or SB containing CHL: (a) $10^{-5} \mathrm{M}$; (b) $10^{-4} \mathrm{M}$. Synaptosomes from CHL-pretreated rats were superfused with SB. After a 35 min superfusion period, all synaptosomes received 2 pulses, separated by a $90 \mathrm{~min}$ wash period with SB alone, one pulse with (-)-nicotine $\left(10^{-6} \mathrm{M}\right)$ (hatched columns) and the other with SB (open columns). The order of the pulses was counterbalanced within each pretreatment group. The vertical axis represents mean ( \pm s.e.mean) peak release, calculated as a percentage of basal release (a: $n=5-6$; b: $n=8-10)$.

quently compared, both treatments resulted in nicotinic blockade prior to the wash-out period, as expected. The nicotinic blockade following in vitro administration of CHL was complete at $10^{-4} \mathrm{M}$ but not at $10^{-5} \mathrm{M}$ (Figure 5). Following the $90 \mathrm{~min}$ wash-out period, synaptosomes that had been exposed in vitro to either of the CHL concentrations showed complete recovery of the nicotinic response (Figure 5). Thus, the effect of the post-wash nicotine challenge was not significantly reduced by pretreatment with either the low $(P>0.1)$ or high $(P>0.2)$ concentration of CHL. In marked contrast, synaptosomes prepared from rats that had received CHL in vivo showed no signs of recovery from nicotinic blockade (Figure 5).

\section{Discussion}

The long-lasting central blockade by $\mathrm{CHL}$ is well documented in in vivo studies using behavioural testing (Clarke \& Kumar, 1983; Clarke, 1984; Reavill et al., 1986; Fudala \& Iwamoto, 1987; Kumar et al., 1987; Mundy \& Iwamoto, 1988; Corrigall et al., 1992; Clarke et al., 1994). Here, we demonstrate for the first time that in vivo administration of CHL results in ex vivo blockade, using an in vitro assay of brain nicotinic receptor function. Remarkably, this blockade persisted even 12 weeks after in vivo pretreatment with CHL, and resisted extensive washing in vitro. We further demonstrate that CHL exerts a selective action, in so far as neither in vivo nor in vitro administration of $\mathrm{CHL}$ altered the responses to high $\mathrm{K}^{+}$buffer or (+)-amphetamine. We are not aware of any other selective nicotinic antagonist that produces such a persistent central blockade.

\section{Is the long-lasting block in vivo due to persistence of chlorisondamine in the CNS?}

At physiological $\mathrm{pH}, \mathrm{CHL}$ is positively charged and does not readily cross the blood brain barrier (Clarke, 1984). Presumably, therefore, any CHL that reaches the CNS following systemic administration of a high dose may be retained for some time. Physical trapping of this sort suggested itself as a possible cause for the long-lasting blockade by CHL. However, the blood brain barrier clearly cannot contribute in synaptosomal experiments, where CHL block was persistent.

What mechanism $(s)$ would underlie the persistent central
nicotinic block following in vivo administration of $C H L$ ?

In the present study, we have demonstrated that extended washing did not effect recovery in synaptosomes prepared from rats pretreated with CHL in vivo. In contrast, a $60 \mathrm{~min}$ wash-out period produced a partial recovery from blockade following in vitro administration of $\mathrm{CHL}$, and this recovery became complete by 90 min wash.

This final experiment therefore demonstrates that the mechanism underlying the acute blockade following in vitro administration of CHL differs from that associated with the chronic blockade occurring after in vivo administration of the drug. The basis for this difference is not clear. Possibly, CHL is transformed in vivo but not in vitro, forming an active metabolite which is more slowly reversible than CHL itself. It is also conceivable that in vivo, the receptors undergo a conformational change, assuming a stable state in which CHL (or a metabolite) is captured. In non-mammalian tissue, Lingle and Neely (Lingle, 1983a,b; Neely \& Lingle, 1986) proposed that, following use-dependent block by CHL, the receptor assumes a stable-blocked state in which CHL would be trapped within the closed ion channel. Whether this proposal, derived from acute in vitro studies, relates to the chronic in vivo blockade produced by $\mathrm{CHL}$ is not clear. Moreover, whereas in the experiments of Lingle and colleagues (Lingle, 1983a,b; Neely \& Lingle, 1986), recovery from blockade by CHL required re-exposure to agonist, such a requirement was not observed in the present study (Figure 4).

\section{Is the chronic blocking action of CHL reversible?}

The turnover rate of CNS nicotinic receptors is unknown. However, nicotinic receptor turnover, where studied in other tissues, has typically been found to occur over a period of hours to a few days at most (Kemp \& Edge, 1987; Higgins \& Berg, 1988; Avila et al., 1989; Fumagalli et al., 1990). A possible effect of $\mathrm{CHL}$ on nicotinic receptor synthesis or on the assembly of the receptor subunits is unlikely, since high affinity $\left[{ }^{3} \mathrm{H}\right]$-nicotine binding appears to be unaltered during persistent blockade by CHL (Clarke et al., 1994). Thus, it is 
likely that over the course of this extended period of blockade, several generations of nicotinic receptors are produced and then degraded. This suggests that an extremely slow dissociation of the active compound from its binding sites cannot by itself explain the persistent central blockade; even if CHL were to bind irreversibly to CNS nicotinic receptors, persistent in vivo blockade would require either efficient recycling of the antagonist, or a reserve of antagonist retained in the brain. Possibly, the long-lasting in vivo blockade by CHL results from a combination of a slow dissociation of the active compound, with some form of physical trapping provided either by the synaptic environment or by the blood brain barrier.

The nicotinic blockade obtained after a single in vivo administration of CHL was not overcome by a high concentration of acetylcholine $\left(10^{-4} \mathrm{M}\right)$ or even by concentrations of nicotine that would be acutely toxic or lethal in vivo $\left(10^{-4} \mathrm{M}\right)$. Circulating concentrations of nicotine in habitual cigarette smokers are typically in the range of $0.1-0.5 \times 10^{-6} \mathrm{M}$, and during active cigarette smoking, transient concentrations several-fold higher may be achieved in the brain (Benowitz et

\section{References}

AVILA, O.L., DRACHMAN, D.B. \& PESTRONK, A. (1989). Neurotransmission regulates stability of acetylcholine receptors at the neuromuscular junction. J. Neurosci., 9, 2902-2906.

BENOWITZ, N.L., PORCHET, H.C. \& JACOB, P. (1990). Pharmacokinetics, metabolism, and pharmacodynamics of nicotine. In Nicotine Psychopharmacology: Molecular, Cellular, and Behavioural Aspects. ed. Wonnacott, S., Russell, M.A.H. \& Stolerman, I.P. pp. 112-157. Oxford: Oxford University Press.

BOURA, A.L.A. \& GREEN, A.F. (1984). Peripheral anti-hypertensives: ganglion and adrenergic neurone blocking agents. In Discoveries in Pharmacology Vol. 2. ed. Parnham, M.J. \& Bruinvels, J. pp. 73-104. Amsterdam: Elsevier.

CLARKE, P.B.S. (1984). Chronic central nicotinic blockade after a single administration of the bisquaternary ganglion-blocking drug chlorisondamine. Br. J. Pharmacol., 83, 527-535.

CLARKE, P.B.S., CHAUDIEU, I., EL-BIZRI, H., BOKSA, P., QUIK, M., ESPLIN, B.A. \& CAPEK, R. (1994). The pharmacology of the nicotinic antagonist, chlorisondamine, investigated in rat brain and autonomic ganglion. Br. J. Pharmacol., 111, 397-405.

CLARKE, P.B.S. \& KUMAR, R. (1983). Characterization of the locomotor stimulant action of nicotine in tolerant rats. $B r . J$. Pharmacol., 80, 587-594.

CORRIGALL, W.A., FRANKLIN, K.B.J., COEN, K.M. \& CLARKE, P.B.S. (1992). The mesolimbic dopaminergic system is implicated in the reinforcing effects of nicotine. Psychopharmacology (Berlin), 107, 285-289.

EL-BIZRI, H. \& CLARKE, P.B.S. (1994). Blockade of nicotinic receptor mediated release of dopamine from striatal terminals by chlorisondamine and other nicotinic antagonists administered in vitro. Br. J. Pharmacol., 111, 406-413.

FUDALA, P.J. \& IWAMOTO, E.T. (1987). Conditioned aversion after delay place conditioning with nicotine. Psychopharmacology, 92, 376-381.

FUMAGALli, G., BALBI, S., CANGIANO, A. \& LMO, T. (1990). Regulation of turnover and number of acetylcholine receptors at neuromuscular junctions. Neuron, 4, 563-569.

GIORGUIEFF CHESSELET, M.F., KEMEL, M.L., WANDSCHEER, D. \& GLOWINSKI, J. (1979). Regulation of dopamine release by presynaptic nicotinic receptors in rat striatal slices: effect of nicotine in a low concentration. Life Sci., 25, 1257-1262.

GIORGUIEFF, M.-F., LE FLOC'H, M.L., GLOWINSKI, J. \& BESSON, M.J. (1977). Involvement of cholinergic presynaptic receptors of nicotinic and muscarinic types in the control of the spontaneous release of dopamine from striatal dopaminergic terminals in the rat. J. Pharmacol. Exp. Ther., 200, 535-544. al., 1990; Russell, 1990). In this concentration-range, nicotine can induce receptor-mediated dopamine release (Giorguieff $e t$ al., 1977; Giorguieff Chesselet et al., 1979; Westfall et al., 1987; Rapier et al., 1988; Grady et al., 1992; El-Bizri \& Clarke, 1994). Thus, it is likely that the receptor subtype(s) that were blocked by $\mathrm{CHL}$ in our experiments would mediate some of the central effects of nicotine encountered during smoking. The persisent and insurmountable antagonism seen following administration of CHL may be of relevance in the context of developing a pharmacological treatment for nicotine dependence.

We wish to thank Drs Sharon Grady, Michael Marks and Allan Collins for generously sharing their expertise, which was indispensable in setting up the release assay. We thank Dr Brian Collier for his valuable comments. We also thank Miss Melanie Reuben for excellent technical assistance. Ciba-Geigy generously donated samples of chlorisondamine. Supported by the Medical Research Council of Canada. H.E.-B. was a Hydro-Quebec Fellow and is an MRC (Canada) Student. P.B.S.C. holds a Senior I Career Award from the FRSQ.

GRADY, S., MARKS, M.J., WONNACOTT, S. \& COLLINS, A.C. (1992). Characterization of nicotinic receptor-mediated $\left[{ }^{3} \mathrm{H}\right]$ dopamine release from synaptosomes prepared from mouse striatum. $J$. Neurochem., 59, 848-856.

HIGGINS, L.S. \& BERG, D.K. (1988). Metabolic stability and antigenic modulation of nicotinic acetylcholine receptors on bovine adrenal chromaffin cells. J. Cell Biol., 107, 1147-1156.

KEMP, G. \& EDGE, M. (1987). Cholinergic function and alphabungarotoxin binding in $\mathrm{PC} 12$ cells. Mol. Pharmacol., 32, $356-363$.

KUMAR, R., REAVILL, C. \& STOLERMAN, I.P. (1987). Nicotine cue in rats: effects of central administration of ganglion-blocking drugs. Br. J. Pharmacol., 90, 239-246.

LINGLE, C. (1983a). Blockade of cholinergic channels by chlorisondamine on a crustacean muscle. J. Physiol., 339, 395-417.

LINGLE, C. (1983b). Different types of blockade of crustacean acetylcholine-induced currents. J. Physiol., 339, 419-437.

MUNDY, W.R. \& IWAMOTO, E.T. (1988). Actions of nicotine on the acquisition of an autoshaped lever-touch response in rats. Psychopharmacology (Berlin)., 94, 267-274.

NEELY, A. \& LINGLE, C.J. (1986). Trapping of an open-channel blocker at the frog neuromuscular acetylcholine channel. Biophys. J., 50, 981-986.

PLUMMER, A.J., TRAPOLD, J.H., SCHNEIDER, J.A., MAXWELL, R.A. \& EARL, A.E. (1955). Ganglionic blockade by a new bisquaternary series, including chlorisondamine dimethochloride. J. Pharmacol. Exp. Ther., 115, 172-184.

RAPIER, C., LUNT, G.G. \& WONNACOTT, S. (1988). Stereoselective nicotine-induced release of dopamine from striatal synaptosomes: concentration dependence and repetitive stimulation. $J$. Neurochem., 50, 1123-1130.

REAVILL, C., STOLERMAN, I.P., KUMAR, R. \& GARCHA, H.S. (1986). Chlorisondamine blocks acquisition of the conditioned taste aversion produced by (-)-nicotine. Neuropharmacology, 25, 1067-1069.

RUSSELL, M.A.H. (1990). Nicotine intake and its control over smoking. In Nicotine Psychopharmacology: Molecular, Cellular, and Behavioural Aspects. ed. Wonnacott, S., Russell, M.A.H. \& Stolerman, I.P. pp. 374-418. Oxford: Oxford University Press.

WESTFALL, T.C., PERRY, H. \& VICKERY, L. (1987). Mechanisms of nicotine regulation of dopamine. In Tobacco Smoking and Nicotine. ed. Martin, W.R., Van Loon, G.R., Iwamoto, E.T. \& Davis, L. pp. 209-224. New York: Plenum Press.

(Received May 4, 1993 Revised September 21, 1993 Accepted September 29, 1993) 